\title{
Upper limb rehabilitation after spinal cord injury: a treatment based on a data glove and an immersive virtual reality environment
}

Iris Dimbwadyo-Terrer, Fernando Trincado-Alonso, Ana de los ReyesGuzmán, Miguel A. Aznar, Cesar Alcubilla, Soraya Pérez-Nombela, Antonio del Ama-Espinosa, Begoña Polonio-López \& Ángel Gil-Agudo

To cite this article: Iris Dimbwadyo-Terrer, Fernando Trincado-Alonso, Ana de los ReyesGuzmán, Miguel A. Aznar, Cesar Alcubilla, Soraya Pérez-Nombela, Antonio del Ama-Espinosa, Begoña Polonio-López \& Ángel Gil-Agudo (2015): Upper limb rehabilitation after spinal cord injury: a treatment based on a data glove and an immersive virtual reality environment, Disability and Rehabilitation: Assistive Technology

To link to this article: http://dx.doi.org/10.3109/17483107.2015.1027293

Published online: 16 Jul 2015.

Submit your article to this journal $\llbracket$

Џ Article views: 47

Q View related articles $\sqsubset$

View Crossmark data $\asymp$ 


\title{
Upper limb rehabilitation after spinal cord injury: a treatment based on a data glove and an immersive virtual reality environment
}

\author{
Iris Dimbwadyo-Terrer ${ }^{1}$, Fernando Trincado-Alonso ${ }^{1}$, Ana de los Reyes-Guzmán ${ }^{1}$, Miguel A. Aznar ${ }^{2}$, Cesar Alcubilla ${ }^{2}$, \\ Soraya Pérez-Nombela ${ }^{1}$, Antonio del Ama-Espinosa ${ }^{1}$, Begoña Polonio-López ${ }^{3}$, and Ángel Gil-Agudo ${ }^{1}$ \\ ${ }^{1}$ Biomechanics and Technical Aids Department, National Hospital for Spinal Cord Injury, Toledo, Spain, ${ }^{2}$ AnswareTech, S.L., Madrid, Spain, and \\ ${ }^{3}$ Nursing, Physiotherapy and Occupational Therapy Department, University of Castilla la Mancha, Talavera de la Reina, Spain
}

\begin{abstract}
Purpose state: The aim of this preliminary study was to test a data glove, CyberTouch ${ }^{T M}$, combined with a virtual reality (VR) environment, for using in therapeutic training of reaching movements after spinal cord injury $(\mathrm{SCl})$. Method: Nine patients with thoracic $\mathrm{SCl}$ were selected to perform a pilot study by comparing two treatments: patients in the intervention group (IG) conducted a VR training based on the use of a data glove, CyberTouch ${ }^{\mathrm{TM}}$ for 2 weeks, while patients in the control group (CG) only underwent the traditional rehabilitation. Furthermore, two functional parameters were implemented in order to assess patient's performance of the sessions: normalized trajectory lengths and repeatability. Results: Although no statistical significance was found, the data glove group seemed to obtain clinical changes in the muscle balance (MB) and functional parameters, and in the dexterity, coordination and fine grip tests. Moreover, every patient showed variations in at least one of the functional parameters, either along $Y$-axis trajectory or Z-axis trajectory. Conclusions: This study might be a step forward for the investigation of new uses of motion capture systems in neurorehabilitation, making it possible to train activities of daily living (ADLs) in motivational environments while measuring objectively the patient's functional evolution.
\end{abstract}

Keywords

CyberTouch, data glove, rehabilitation, spinal cord injury, upper limbs, virtual reality

\section{History}

Received 1 September 2014

Accepted 5 March 2015

Published online 16 July 2015

\section{Introduction}

Upper limbs (UL) are affected in more than 50\% of cases among people with spinal cord injury (SCI) [1]. In contrast with lower limbs, upper limbs have extensive functionality due to the mobility of numerous joints that can execute fine movements, thanks to a complex neuromuscular control. Upper limb and trunk motion impairment caused by SCI have a high impact on the independence and quality of life of the affected person.

In paraplegia, arm functioning is spared, but, depending on the level of injury, the trunk and legs may be affected to a different degree. At the level of thoracic injuries T1-8, there is most often

Address for correspondence: Iris Dimbwadyo-Terrer, MsC., Occupational Therapist, Biomechanics and Technical Aids Department, National Hospital for Spinal Cord Injury, Toledo, Spain. Tel: +34 925247779. E-mail: idimbwadyo@ sescam.jccm.es control of the hands, but usually poor trunk control as a result of the lack of abdominal muscle control [2], necessary for body postural balance and required for generating a stable base for upper limb movements, which in turn are necessary to execute activities of daily living (ADLs). These activities are basic to higher levels of functioning, and improvement of these abilities is likely to have considerable impact on the patients' level of handicap and health-related quality of life [3]. Because daily life is filled with tasks that require rapid and discrete aiming movements [4], interventions to increase reaching movements' speed are important for people with SCI. The main muscles for flexing the trunk, necessary to perform functional ADLs and reaching movements are rectus abdominis, and superior and inferior oblique. These muscles are innervated by the thoracoabdominal nerves at the level of T7-T12, so the injuries above these levels affect trunk's flexion and, therefore, reaching movements [5]. 